\title{
Smart Audit using Information Technology
}

\author{
Gyancity Research Lab, India \\ mnachandigarh@gmail.com
}

\begin{abstract}
Smart audit using Information technology, is assessment of the management with the help of information technology methods. The evidence obtained is used to determine the authenticity and credibility of the organisation. The assessment is made with the help of financial statement audit and internal audit
\end{abstract}

Keywords- Information technology, auditing, management, documentation, artificial intelligence.

\section{Introduction:}

Nowadays almost every organisation use information technology product and service during their daily operations. While we are living the world where time is money, Information technology (IT) has saved lot of time by simplifying the tedious process involved during audit. The use of technology and digitization of business has changes the way the external audits are conducted. The increasing use of technology has made auditors to enhance their toolset. Globally, companies, the audit profession, professional bodies and regulators are increasing their focus on the impact of technology. There are clear benefits that technology can bring from operational efficiency to financial inclusion and greater insights Technology is changing the way business is conducted and data is analysed. There is an increasing focus on data management; 'Know Your Data' (KYD) is the new buzzword replacing 'Know Your Client' (KYC) as shown in Fig. 1.[1]

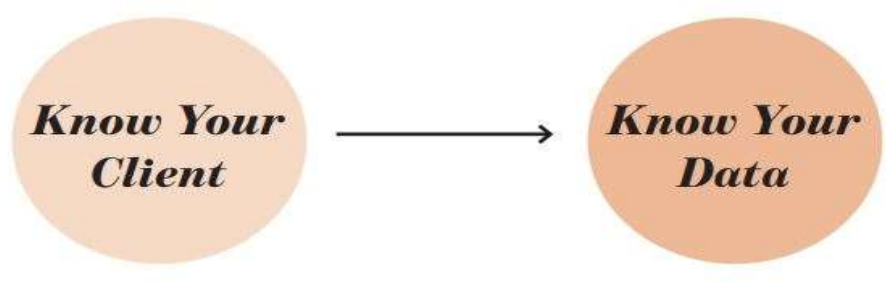

\section{Present involvement of IT in audit}

Fig.1. KYC and KYD

Presently computer with fusion of internet has taken over all the organizations which lead to use of the same by auditors to cope up with pace of changing world.

Computer-assisted audit techniques (CAATs) or computer-assisted audit tools and techniques (CAATTs) has been seen a growth in recent years in profession of it audit. CAATS is automate the IT audit process with the help of computer. CAATs usually include applying of basic productive software and applications like spreadsheet, word processor, and text editing program. Talking about more advance programs it includes using of statistical analysis and business intelligence tools. The traditional method of auditing allows auditors to build conclusions based upon a limited sample of a population, rather than an examination of all available or a large sample of data.

CAATTs, addresses these problems. CAATTs, as it is commonly used, is the practice of analysing large volumes of data looking for anomalies. A well designed CAATTs audit will not be a sample, but rather a complete review of all transactions. Using CAATTs the auditor will extract every transaction the business unit performed during the period reviewed. The auditor will then test that data to determine if there are any problems in the data. In simpler way, CAATTs is any computer utility which enhance the audit process though it refers to any data analysis and data extraction software 
which include spreadsheet(e.g. excel), database(e.g. access), statistical analysis(e.g. SAS), generalized audit software (e.g. ACL, Arbutus, EAS), business intelligence(e.g. Crystal Reports) etc.

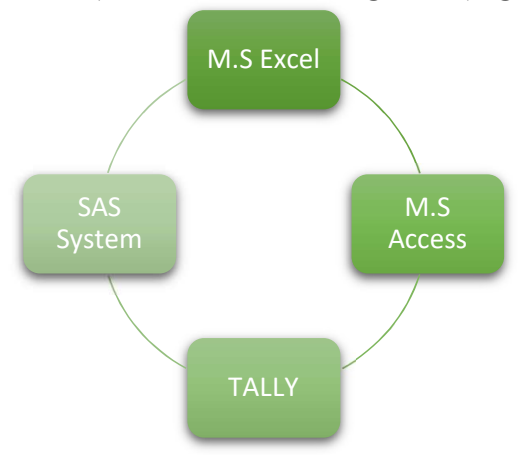

Fig.2. CAATT Program Tools

2.1 Audit software as asset-

1) Audit software are individualistic, does not involve the system being audited and they use read- only copy of the file to avoid data degradation.

2) Sampling for audit is used on routine basis.

3) It provided detailed of each test performed during the process that can be used as documentation in the auditor's work paper.

2.2 Audit oriented program and software perform the various functions:

1) Sample extraction

2) Data queries

3) Missing sequence identification

4) Data analysis

5) Comprehensive calculation

6) Identifying delicacy of work

7) Cross tabulation

8) Pivot table creation

9) Data stratification

\subsection{Some other uses:}

Besides using it as data analysis software, it is also used throughout the auditing in the following ways:

\subsubsection{Creation of soft copy}

Gathering the soft copy or electronic work paper on a centralized database allow the auditor to navigate through the current and achieved working paper with ease. The centralised database enable the auditor to coordinate current audit and get necessary details from prior or related work. Additionally, the auditor can standardize the audit form and format which increase ease of doing work.

\subsubsection{Identifying Fraud}

CAATs provides auditor superpower like feature which help to identify the unexpected or unexplained pattern in data which may indicate fraud. Even if CAATs is complex, data analysis provides many benefit in prevention and detection of fraud.

CAATs assist auditor in the following ways.

\subsubsection{Analytics}


Analysing financial and non-financial data to assess whether account balance appear legit, which help in evaluating financial aspects.(AU 329). Examples are including company ratios, trends and benford's law test[5]

\subsubsection{Reports of data analysis}

Specific audit commands can be used like filtering records and joining data files to generate specific report.

\subsubsection{Maintain regular surveillance}

Regular monitoring is an ongoing process which include acquiring, analysing, reporting on business data to evaluate and respond to operati0onal risk of business. As auditor to ensure a detailed approach to acquire, analyse and report on business data, they must regularly have surveillance use activity on all computer system, business transactions and process, and application of managerial controls.

\subsubsection{Curb stoning in Surveys-}

Curb stoning is the term where surveyor completes the survey form by making up the data. As data should conform to Benfor's law, this practice can be detected with the help of CAATTs which give the doing such function.[6]

\subsubsection{Foresee Audit-}

Daily new drugs are being discovered for various cancer. Mobile phone with the help of algorithmic and pinch of artificial intelligence can now recognize human face better than human itself. The auditing can't keep the pace at which technology is used but the profession must innovate and evolve, and yes it is also developing.

One of the most Buzzing areas of innovation at present is Artificial Intelligence (AI). AI is the enhancement in the information technology which previously were dependent on human intelligence to perform various task. Cognitive Technology or say Artificial intelligence can analyse and learn vast amount of data quicker and more precisely than any human. It can determine at what level of organization the performance lack. It can also help know how and where things are compromised and what measure need to be taken to improve such areas [7].

Also artificial intelligence is capable of learning itself as it goes along, allowing it to widen and improve its knowledge and analytical capabilities, like professional auditors do and build their skill during the course.

This minimise the manual work of auditor, like providing confirmation response and counting inventories. Doing so enable the auditor to focus more on the quality of audit by evaluating advance analytics, dedication more on professional judgement, and proving bigger insight view of the organisation[9]

Document review is one of the area where auditor are taking advantage of Artificial technologies. Reading all the contract terms and understanding the technicalities used to be a time consuming process. Artificial intelligence plays its role vary effectively here, with the help of AI, an auditor now can see through contract term and key points and all other necessary details with in fraction of seconds and can ensure that there are not irregularities, also as AI keep learning, this can help AI understanding concepts in the documents improving AI on day by day basis, which enable it to do lighting fast analytics of the data. This lead to increase in quality and correctness of the report

It is shown in of of the researches that it is possible to forecast the variability of company's stock price with the help of analysing financial statement through AI and machine learning. Using AI 
to make audit process timely and accurately efficient and having deeper insight of company is one of the ways audit profession is innovating.

\section{Process of financial reporting:}

Now days IT is used on daily basis in almost every organization, such as in maintain accounts or recording entireties, this also help them in getting transaction total at tips, making adjustment (including journal entries) into general ledgers and preparing financial statements such as balance sheet, profit \& loss account. Such organization are considered of ancient civilization where auditor have to examine manually prepared cash- receipts journal and cross check registers, calculate monthly totals to manually written entries in general ledger an evaluating manually prepared worksheets. [11]

\subsection{Digital signatures}

Now days as business entities going digital, their submission of the taxes and return also need to be done electronically, like submission of good and service tax or filling company annual returns or completing an agreement or contract. In past all such work is needed to be typed on paper and it was mandatory to give handwritten signature on that paper to make it contract or agreement. Handwritten signature were considered as consent of the person for the term mentioned on paper which can be anything like to pay tax or obligation to pay money on completion of certain work etc. But now days digital signatures have taken place of manual signatures, By digital signature unnecessary delay in transferring manual paper have been reduced, one can digital sign the document through computer and submit the same to any concerned person in any part of world electronically.[12]

\subsection{Electronic signatures}

For business entities that conduct operations online using electronic commerce, electronic signatures have become rather common. In the past, all contracts and agreements were typed on paper, with handwritten signatures that provided auditors with the identity of the signers and their actual signatures, indicating agreement with the content of that particular document.[12]

In a recent Deloitte survey, an overwhelming number of respondents agreed that audit technology was important. Of those surveyed, 84 percent of financial statement preparers, 76 percent of audit committees and 70 percent of financial statement users said that these tools should be used more extensively. With this in mind, there are three ways that auditors can advance their firm in the use of audit technology:

1) Standardized documentation

2) File storage and file sharing

3) Automated expected values and threshold analysis

The benefits of standardizing audit documentation are somewhat obvious, as it has fewer opportunities for error as well as compliance with audit and review guidelines. Standardization also can help firm communicate the details of financial statement materials in a clearer and more concise manner. Developing standardization is possible through excel and onsite software. Your ability to standardize, however, may be limited to your office and could have multi-user limitations. Storing and sharing files across globally-accessible web-based software will enable you to standardize processes across multiple users in your firm. Web-based data centres offer a number of benefits to companies who want to reduce costs, improve redundancies, increase security and ensure maximum system uptime. Managed data centres provide customers with best-in-class infrastructure, while allowing customers as much, or as little hands-on management. Storing your financial data in web-based software ensures security as well as transferability between firm members and your clients.

\section{Conclusion}


We can say that technology benefits any organization or auditor by providing access to large data which was which otherwise wise impossible to compile and analyse within given place and time without technology. Analysing the data through technology provide elaborated insight to the client industries and make benchmarking more directed. Using software as service help the streamline of audit efficiently. The quick analysis of data enable auditor to focus more on making review and help in increasing the credibility of the audit. Looking in the future, there are many ways IT can enhance the audit process using the abundant data resource. With quick audit process, the time is not far away when we consider audit as ongoing process instead of audit being one time process in a year. Additionally, Artificial intelligence (AI) will continue to assist auditor identify opportunity and learn itself when looking at client financial data. All this will enable financial reporting more accurate and feasible.

Compliance and advisory service will get most benefit when their collaboration will increase. The tried and tested audit method will help figuring out the different methods an accountant can help their client business becoming more flourished.[13]

\section{REFERENCE}

[1] UNDERSTANDING THE IMPACT OF TECHNOLOGY IN AUDIT AND FINANCE, C ICAEW 2018

[2] https://en.wikipedia.org/wiki/Productivity_software

[3] https://en.wikipedia.org/wiki/Spreadsheet

[4] https://en.wikipedia.org/wiki/Spreadshhttps://en.wikipedia.org/wiki/Word_processorseet

[5] https://en.wikipedia.org/wiki/Benford\%27s_law

[6] https://en.wikipedia.org/wiki/Computer-aided audit tools

[7] How Technology Is Transforming the Audit, https://www.forbes.com/sites/kpmg/2016/11/23/how-technology-istransforming-the-audit/\#15322172716c Marc T. Macaulay Brand ContributorKPMG Nov 23, 2016

[8] How Artificial Intelligence Can Boost Audit Quality, http://ww2.cfo.com/auditing/2015/06/artificial-intelligencecan-boost-audit-quality/ Jon Raphael and 10Rule, Contributors

[9] How Technology Is Transforming the Audit, Marc T. Macaulay Brand Contributor KPMG BRANDVOICE

[10] How Artificial Intelligence Can Boost Audit Quality, Jon Raphael and 10Rule, Contributors

[11] IT and the Audit, https://www.journalofaccountancy.com/issues/2001/sep/itandtheaudit.html GEORGE H. TUCKER, September 1, 2001

[12] Technology Changes the Form and Competence of Audit Evidence By Paul Caster and Dino Verardo, Jan 2007 Issue

[13] The benefits of audit technology, August 25, 2015 by Sageworks 